\title{
EL TRASTORNO DE LA MORAL EN EL LAZARILLO
}

En el Othello de Shakespeare (IV, 2), Emilia, falsamente acusada de haber mantenido relaciones ilícitas con el Moro, dice a lago que los calumniadores le han vuelto al revés el ingenio: "turned your wit the seamy side without". Así se acuñó una expresión que sigue siendo de uso corriente en la lengua inglesa. The seamy side es el lado de un vestido que muestra las costuras. Se habla sobre todo de the seamy side of life, el lado sucio y feo de la vida, que de ordinario está oculto; la metáfora evoca una prenda vuelta al revés, que pone de manifiesto la parte basta, fea, impregnada por los sudores y olores del cuerpo, pero sin la cual no sería posible la nitidez y la limpieza que se ven por fuera. Es evidente que el Lazarillo de Tormes refleja the seamy side de la vida española de mediados del siglo xvi. Pero, al mismo tiempo que descubre los bajos fondos de la sociedad española, retrata también a un hombre cuyos valores morales están vueltos al revés.

No se ha analizado lo bastante este aspecto de la obra, a pesar de que la clave para ello se nos ofrece ya en el Tratado I: "Huelgo de contar a vuestra merced estas niñerías, para mostrar quánta virtud sea saber los hombres subir, siendo baxos; y dexarse baxar, siendo altos, quánto vicio" (pp. 78-79) ${ }^{1}$.

Dentro de la sociología tradicional del pensamiento cristiano, la doctrina expuesta por Lázaro es heterodoxa. Calderón expresa el punto de vista ortodoxo en $E l$ gran teatro del mundo: el mendigo, el labrador, el rey, todos reciben sus estados de Dios; no tienen ni el derecho ni la posibilidad de cambiar de estado. Querer subir en el mundo es rebelarse contra la voluntad divina, es pecar ${ }^{2}$. Así, pues, al equiparar la moral con el mejoramiento material, Lázaro

1 Citamos el Lazarillo por el texto de Clás. cast., ed. de 1959, modernizando la acentuación.

2 Véase A. A. PARKer, The allegorical drama of Calderón, Oxford-London, 1943, pp. $146 \mathrm{ss}$. La teoría ortodoxa subsiste aún en las sociedades no revolucionarias. Por ejemplo, en la Inglaterra victoriana se compuso un himno evangélico, que sigue cantándose en nuestros días, según el cual entre las cosas "claras y bellas, sabias y maravillosas" creadas por Dios, se cuenta esa jerarquización social: "el rico en su castillo, el pobre en su portillo". 
llama virtud a un pecado. En la esfera de la moral, la narración es iconoclasta.

Si estudiamos la manera como se emplea en la novela el epíteto moral más frecuente, bueno, fácilmente llegaremos a comprobar esto que acabamos de decir. La madre de Lázaro decide guiarse en la vida por el precepto moral contenido en un refrán popular: "Arrímate a los buenos y serás uno de ellos" (p. 68) ${ }^{3}$. Los "buenos" a quienes se allega son unos estudiantes y unos mozos de caballos del Comendador de la Magdalena, para los cuales guisará la comida y lavará la ropa: buenos son los que le facilitan el dinero que le hace falta para comer, los que le aseguran la supervivenciat. Al final del libro, cuando el Arcipreste le dice a Lázaro una cosa que a ambos les consta ser mentira, a saber, que si la mujer de Lázaro entra y sale de casa del propio Arcipreste, ello es sin menoscabo de la honra de: su marido, se cita el mismo refrán: "Señor, le dixe, yo determiné de arrimarme a los buenos" (pp. 238-239). Este bueno a quien se arrima Lázaro es un bueno profesional, un clérigo; pero un clérigo que tiene por manceba a la mujer que ha sido unida sacramentalmente a Lázaro por acción de la Iglesia a quien ese clérigo sirve. La relación adúltera debería forzosamente calificarse de mala. La acción se desenvuelve así dentro de un marco constituido por un precepto moral cuyo sentido ha sido vuelto al revés.

Entre los dos extremos del libro el autor se esfuerza por dar a la palabra bueno un sentido especial, aplicable únicamente al mundo del picaro, mundo trastrocado, vuelto al revés. El libro tiene por fin ensalzar a "los que, siéndoles contraria [la Fortuna], con fuerça y maña remando salieron a buen puerto" (p. 64), es decir, a un puerto seguro. En efecto, lo bueno en el Lazarillo es lo seguro, lo que conviene al bienestar del que lucha contra la adversa Fortuna. La experiencia va enseñando a Lázaro lo que será para él la verdadera significación de la palabra. "Procura de ser bueno -le dice su madre al despedirse para siempre- y Dios te guíe..., válete por ti" (p. 76 ). Para llegar a ser bueno hay que saber valerse por sí mismo. Cuando queda descalabrado por el toro de piedra, Lázaro decide "que me cumple... pensar cómo me sepa valer" (p. 78). Todavía es incapaz de formar un juicio moral. Empieza por llamar "bueno" (p. 79) al ciego, aunque "jamás tan auariento ni mezquino hombre no vi” (p. 81). Al llegar a la página 88 leemos que en la opinión de Lázaro el amo ya es "malo". ¿Por qué el cambio de adjetivo? Porque,

a Véase F. Courtney TARr, "Literary and artistic unity in the Lazarillo de Tormes", PMLA, 42 (1927), p. 418.

4 En la España antigua se distinguían tres clases de vida: la eterna, la del honor y la temporal. Esta última, menospreciada por los moralistas por ser tan poco duradera, consistía en mantener la unión estrecha entre alma y cuerpo; la ejemplifica el Clarín de La vida es sueño. Véase mi artículo "Apenas llega cuando llega a penas", $M P h, 57$ (1960), $240-244$. 
habiendo penetrado la psicología del ciego, Lázaro ve ya que el sadismo de su amo se opone a su bienestar personal. Había que descontar, al hacer este juicio, la auténtica caridad del ciego, su "bondad" según la ética cristiana: "Desde aquella hora quise mal al ciego y, aunque me quería y regalaua y me curaua, bien vi que se hauía holgado del cruel castigo" (p. 88). Desde este momento de revelación, aunque no dejará de reconocer lo que debe al ciego por sus excelentes lecciones de picardía, Lázaro le llamará "peruerso" y "malo", y declarará que "por su maldad me venían tantas persecuciones" (p. 100). Al final del Tratado II el clérigo de Maqueda despide a Lázaro con el consejo "busca amo y vete con Dios"' (p. 145); al principio del Tratado III le ayudan "las buenas gentes" de Toledo, quienes le repiten el mismo consejo con una ligera pero significativa variante: "busca, busca vn buen amo a quien siruas" (p. 147). En efecto, lo que le hace falta a Lázaro es un buen amo, o sea un amo que le dé de comer. Se encuentra -o "le topa.Dios". (p. 148)5- con el escudero venido a menos. Pronto reflexionará, repasando la serie de amos avaros, hipócritas, empobrecidos: “'Maldita tanta medicina y bondad como aquestos mis amos que yo hallo hallan en la hambre!" (p. 154). Pero, aunque no lo reconozca, la Fortuna empieza a sonreírle. Se hace vendedor de agua: ha subido el primer escalón para alcanzar una "buena vida" (p. 229). El último escalón de su ascenso lo conquista cuando hacia el final de la obra le dice a su mujer que siga visitando al Arcipreste, "pues estaua bien seguro de su bondad" (pp. 239-240). La bondad de la casada infiel -la hipocresía convenida entre él y ella y el sacerdote- es lo que más le conviene en este momento de su carrera. Lo bueno es lo provechoso.

¡Cuántas veces habla Lázaro de su provecho y de cómo piensa aprovechar las circunstancias de su vida! Es su gran obsesión. Es la fuente de sus conceptos morales. Cuando va por la calle pensando de qué manera ha de gastar el real venido a manos del escudero, considera "en lo que lo emplearía, que fuesse mejor y más proue-

5 Lázaro ve la intervención divina en cada encuentro y en cada suceso que le son favorables. "Dios le cegó [al ciego] aquella hora el entendimiento (fue por darme dél vengança)", dice cuando su amo se estrella contra el poste (p. 105). El calderero que le facilita la llave del arca es un ángel enviado por Dios (p. 129). El proyecto de "medrar" casándose con la manceba del Arcipreste también le fue sugerido por Dios: "quiso Dios alumbrarme y ponerme en camino y manera prouechosa" (p. 232). Si Dios es la fuente del bien, es natural que piense así el muchacho, con su interpretación materialista de lo bueno. Se tergiversa su noción de la providencia en razón directa con la perversión de su idea de lo bueno. No confunde nunca a la Fortuna con la providencia. Desde el prólogo -donde quiere que sus lectores "vean que biue vn hombre con tantas fortunas, peligros y adversidades" (p. 64)- hasta el último Tratado, la Fortuna no cesa de serle contraria. Sólo en las palabras finales puede concebir que sea una cosa buena: "Pues en este tiempo estaua en mi prosperidad y en la cumbre de toda buena fortuna" (p. 243). 
chosamente gastado" (p. 183). Abre el arca del clérigo de Maqueda con su "desaprouechada llaue, sin esperança de sacar prouecho" (p. 131). Observa que el único interés que entre los fieles suscitan las bulas del falso buldero consiste en su provecho. En su ascenso gradual por la vida, Lázaro, cuando se hace pregonero, llega a aprovechar incluso el provecho de sus vecinos: "tanto, que en toda la ciudad el que ha de echar vino a vender o algo, si Lázaro de Tormes no entiende en ello, hazen cuenta de no sacar prouecho" (pp. 233234). El provecho para él es el manantial de toda moral, incluso de la honra. Si según el Arcipreste la mujer de Lázaro "entra [en mi casa] muy a tu honrra y suya", la gente no dejará de comentar desfavorablemente el suceso. Pero, sigue aconsejando a Lázaro, "no mires a lo que puedan dezir, sino a lo que te toca, digo a tu prouecho", (p. $23^{8}$ ). La honra de su mujer, aunque sea mentira, equivale al provecho. Lo que aprovecha da honra. QQué distancia hay entre este precepto y el sentimiento del honor que tienen las clases nobles en la literatura, desde los libros de caballerías hasta los dramas de honor! Éstos pueden permitirse el lujo de atender a la moral cristiana -que es la virtud- y a la moral laica -que es el honor-; para Lázaro, la moral consiste primero en no dejarse morir de hambre $y$, sólo después de cumplido este fin primario, en medrar ${ }^{6}$.

"Honra y provecho no cabe en un saco", reza el adagio. Comenta Covarrubias: "el hombre honrado no ha de ser interesal". Para Lázaro, como se ha visto, esta sentencia no vale. La honra no es más que una apariencia. Que el Arcipreste le diga que su mujer es honrada, que las malas lenguas digan lo contrario, todo es uno. El provecho, en cambio, es una parte de la realidad cotidiana que se puede medir con la satisfacción del apetito. La ilusión de la honra, sin embargo, no puede menos de suscitar el interés más vivo de Lázaro, porque sintetiza la moral mundana de sus superiores en la escala social. "¿Es el autor quien se expresa así por boca de Lázaro?”, pregunta Marcel Bataillon. Y contesta: "Seguramente. También es Lázaro, cuyo ser todo protesta contra la superstición del honor" ?. Tal vez sea así. Pero muy lógico es suponer que la moral de Lázaro, que trastorna no sólo la virtud cristiana sino también la honra profana, es un punto de vista teórico, y el libro todo un ensayo por investigar las consecuencias sociales y personales de una moral pervertida ${ }^{8}$.

Es curioso notar cómo, aunque en la narración protesta Lázaro

${ }^{6}$ En el último Tratado, Lázaro adopta como su nuevo fin en la vida el de medrar. Véase la p. 232.

7 El sentido del "Lazarillo de Tormes", Paris, 1954, p. 25.

8 Pensamos en algo asi como la técnica empleada por Calderón en su auto sacramental No hay más fortuna que Dios: la acción transcurre en la mente del Demonio, quien se imagina las consecuencias posibles de un trastorno de la sociología tradicional. 
con tanta vehemencia contra la "negra, que dizen, honrra" (p. 181), en su Prólogo explica que lo que le ha movido a componer su autobiografía ha sido la honra. Citando a Cicerón, asegura que los libros se escriben porque sus autores codician la fama literaria: "la honra cría las artes” (p. 62). Para ganar honra, él, que no la tiene, escribe su vida, dedicándola a un mecenas honrado. ¿Con cuánta ironía escribiría estas palabras! Ya que por el concubinato de su mujer y por el pecado del Arcipreste ha resuelto el problema de vivir, de seguir respirando, puede aspirar ahora a la vida de la fama. Es ésta la última meta de su ascenso por la vida.

Pero desde la altura que ocupa ahora no se olvida de sus comienzos humildes ni del afán inteligente con que supo llegar "a tan buen puerto". Ha escrito su vida "por que consideren los que heredaron nobles estados quán poco se les deue, pues fortuna fue con ellos parcial, y quánto más hizieron los que, siéndoles contraria, con fuerça y maña remando salieron a buen puerto" (p. 64). La intención del libro es ensalzar a los hijos de sus obras (tan exaltados también por Cervantes) y desprestigiar a los hijos de algo (tan estimados por los ingenios convencionales de la época). No hemos de ilustrar este hecho con el justamente celebrado episodio del escudero, que lleva a Lázaro a exclamar: “ $O$ Señor, y quántos de aquéstos deuéys vos tener por el mundo derramados, que padescen por la negra que llaman honrra, lo que por vos no suffririan!' (p. 163), contrastando de este modo la moral mundana con la divina. Mientras vive con el escudero, Lázaro queda perplejo ante lo absurdo, lo arbitrario, lo necio y lo desaprovechado del sentimiento del honor que tiene este hombre nacido por casualidad con tal patrimonio espiritual. El episodio entero no aspira más que a deshacer la autoridad que en el mundo y entre el vulgo tiene el sentimiento del honor.

Más sutil es la manera como Lázaro muestra the seamy side del honor volviendo al revés la fórmula de los libros de caballerías. Si Amadís se llama de Caula, él se llama de Tormes. Si el Doncel del Mar recién nacido se halla en el agua del océano, Lázaro recién nacido se halla en el agua de un molino del río Tormes. Para comprender a Amadís el lector tiene que saber muchos detalles de su ascendencia, su niñez y su juventud; lo mismo en el caso de Lázaro (cuya vida de niño no se nos describe por ningún prurito determinista o positivista). Los antecedentes del protagonista interesan para que lo interpretemos bien: el padre de Lázaro -que estará en la gloria porque "padesció persecución por justicia" (p. 66)- murió "como leal criado" (p. 68) en el servicio de un caballero que servía él mismo a su rey en una campaña contra los moros. Dado que sus origenes representan el reverso de los del héroe caballeresco, es inevitable que llegue a formarse una idea pervertida del honor. Censura el honor del escudero. Pero a la vez va forjándose una idea 
propia del honor, muy sui generis, una noción tergiversada, análoga al sentimiento de honra que se supone tienen los ladrones. No quiere nombrar "por su honrra" (p. 219) el lugar donde el buldero hizo el milagro de la cruz caliente. De las ganancias que salen de su vida de aguador "ahorré para me vestir muy honrradamenle de la ropa vieja" (p. 23o). Se resigna a creer que su mujer -la concubina del Arcipreste- es honrada.

Góngora, Quevedo, Gracián se empeñarán, en el siglo xvn, en presentarnos al mundo como un tejido de ilusiones. Para Calderón esta vida es un sueño y la realidad reside únicamente en la ultratumba; lo único que existe en este mundo -lo único que real y verdaderamente existe- es la moral eterna (el principio altruista aprendido por Segismundo) y la moral temporal (el afán de Rosaura por mantener intacta su honra). El autor del Lazarillo, en el siglo xvi, nos revela un mundo aún más engañoso, donde los rasgos externos son reales por ser tangibles, pero donde la moral es tan inestable como la realidad física lo será para los escritores barrocos. Es el suyo un punto de vista más subversivo que el de sus sucesores literarios. Investiga el problema del ser y del parecer en su zona más sensible.

Los amos de Lázaro parecen ser lo que no son. El ciego parece bondadoso y es cruel; el clérigo de Maqueda parece liberal y es mezquino; el escudero parece un caballero bien acomodado y es un vanidoso sin dinero; el buldero parece un devoto entusiasta y es un tramposo irreverente y avaro; el Arcipreste parece de los buenos y es lujurioso. El problema modernísimo del ser y del parecer se concibe, sin embargo, en los términos resueltamente medievales de la moral: en este mundo todo es hipocresía. No se trata, como haría un escritor de nuestros días, de subrayar las diferencias que hay entre lo exterior y lo interior para insistir en la máscara que llevan los hombres; tampoco se trata, como harían en el barroco, de sacar moralejas del perfil engañoso de las cosas. Los personajes del Lazarillo presentan conscientemente y a sabiendas un aspecto que contradice su íntimo ser. $\mathrm{Y}$ lo hacen por engañar a los demás con fines innobles - las más de las veces por pecar, porque no tienen más remedio que pecar. Son hipócritas en su médula misma. Esto es lo que cuenta Lázaro a su mecenas Dives ${ }^{9}$.

Lo que distingue a Lázaro de sus amos es su honradez inicial. Si su moral está trastornada es que responde a las exigencias íntimas de su ser, a sus necesidades más bien físicas que espirituales. Subordina el honor al hambre, lo bueno a lo provechoso. Pero es esencialmente un muchacho honrado: hay plena coherencia en él entre la

9 El "vuestra merced" a quien Lázaro dirige su obra es, sin duda alguna, uno de "los que heredaron nobles estados" y de los que han de aprender por su lectura "quán poco se les deue" a los de su clase. No vacilemos en llamarle Dives. El Lazarillo está lleno de alusiones bíblicas y litúrgicas. 
apariencia y la realidad. Sólo al final, cuando llega a la cumbre de la prosperidad a él asequible, aprende a ser hipócrita, a conformarse con la mentira del Arcipreste, llamando "honrada", de dientes afuera, una situación que su corazón reconoce como deshonrosa. La novela nos enseña la corrupción moral de un muchacho fundamentalmente bueno. Su integridad, su honradez (esencial si no formal) quedan desmoronadas por la fuerza de la hipocresía universal. Partiendo de una moral condicionada por el instinto de perseverar en su existir (moral de orden inferior a la religiosa sin duda, pero, dadas las circunstancias de su vida, admirable en cierto sentido), el autor la va sustituyendo por una inmoralidad corriente, que es la hipocresía. Lázaro es egoísta sólo dentro de límites bien marcados: no quiere morirse de hambre. Fuera de estos límites es capaz de acciones altruistas. Sus amos están entregados todos a la satisfacción desenfrenada de sus veleidades personales, sin pensar en las consecuencias que habrán de sufrir sus prójimos. El egoísmo desbordante de los amos acabará por contagiar a Lázaro. Se integrará en el seamy side de la vida.

BRUCE W. WARDROPPER

Duke University. 